\title{
ANALISIS PENERAPAN SISTEM PENGENDALIAN INTERN PEMERINTAHAN (SPIP) PADA SATUAN KERJA PERANGKAT DAERAH (SKPD) KABUPATEN ACEH BESAR
}

\author{
Andika Restu Adhitya ${ }^{1}$, Jalaluddin ${ }^{* 2}$ \\ ${ }^{1,2}$ Program Studi Akuntansi Fakultas Ekonomi Universitas Syiah Kuala \\ e-mail: andikaadhitya69@gmail.com ${ }^{1}$,jalaluddin.fe@ unsyiah.ac.id ${ }^{* 2}$ \\ * Corresponding Author
}

\begin{abstract}
Riset ini bertujuan untuk mengetahui gambaran penerapan Sistem Pengendalian Intern Pemerintah (SPIP) pada Satuan Kerja Perangkat Daerah (SKPD) Kabupaten Aceh Besar. Riset ini merupakan riset deskriptif, dengan teknik analisis kualitatif. Subjek dalam riset ini ialah meliputi Kabid sumberdaya kesehatan dinkes, Kabid Pembinaan Ketenagaan Dinas Pendidikan, Kabid pengendalian dari DPMPTSP, Kabid Keuangan BPK, dan Kabid Riset dan Pengendalian dan kerjasama pembangunan Bappeda. Pengumpulan data dilakukan dengan menggunakan wawancara dan dokumentasi. Teknik analisis data yang dilakukan menggunakan pendekatan model Miles \& Huberman dalam proses analisis data. Miles \& Huberman (Sugiyono, 2015:337). Hasil riset menunjukan bahwasanya lingkungan Pengendalian pada SKPD Kabupaten Aceh Besar Hal ini diwujudkan melalui pembentukan etika, moralitas, integritas, kejujuran, disiplin, kompetensi, komitmen dari para pelaku aktivitassupaya mampu melakukan tata kelola yang baik. Penyidik meninjau konsistensi SKPD Kabupaten Aceh Besar untuk melakukan unsur-unsur pengendalian lingkungan dengan baik dan sesuai dengan Peraturan Pemerintah Nomor 60 Tahun 2008 tentang SPIP. Elemen pemantauan dari survei kemudian menunjukkan bahwasanya JPCS Kabupaten Aceh Besar melakukan elemen pemantauan tersebut sesuai dengan Peraturan Pemerintah Nomor 60 Tahun 2008. Dari lima unsur SPIP di SKPD Aceh Besar, telah dilaksanakan dengan baik dan memiliki komitmen yang kuat terhadap pelaksanaan SPIP
\end{abstract}

Keywords: Sistem Pengendalian Intern Pemerintahan, Satuan Kerja Perangkat Daerah Kabupaten Aceh Besar

\section{Pendahuluan}

Pengenalan sistem pemerintahan di Indonesia terlibat dengan Undang-Undang Nomor 22 Tahun 1999 tentang Pemerintahan Daerah, diubah dengan Undang-Undang Nomor 32 Tahun 2004 tentang Pemerintahan Daerah. Menurut ayat 5 Pasal 1 Undang-Undang Nomor 32 Tahun 2004, otonomi daerah merupakan hak, kewenangan, dan tugas daerah otonom untuk mengatur dan mengurus urusan negara dan kepentingan masyarakat setempat sesuai dengan ketentuan peraturan perundang-undangan. Otonomi daerah memberikan tanggung jawab dan kewenangan kepada pemerintah daerah untuk menyelenggarakan pemerintahan daerah secara efektif, efisien, transparan, dan akuntabel.

Tata kelola yang baik memerlukan kemampuan untuk mengelola keuangan daerah yang efisien, efisien, transparan, akuntabel dan memberikan manfaat yang nyata.. Dalam menghadapi perkembangan kemajuan yang meningkat penting adanya pengendalian intern pada suatu instansi pemerintahan untuk menunjang keberhasilan instansi tersebut. Seluruh fungsi yang ada pada instansi tersebut harus direncanakan dan dikendalikan dengan sebaik-baiknya supaya lebih efektif untuk menjaga kelancaran operasi pemerintahan tersebut. Instansi pemerintah juga dituntut untuk memperhatikan suatu sistem pengendalian intern yang baik sesuai dengan prinsip-prinsip yang berlaku, sehingga manajemen mempunyai rencana pengendalian yang terarah yang mampu mendukung tercapainya tujuan yang telah ditetapkan pemerintah (Pratiwi, 2012).

Pengendalian internal merupakan salah satu kunci utama suatu instansi untuk mencapai tujuannya, baik itu instansi swasta yang untuk instansi pemerintah 
komersial dan non-komersial. Internal control merupakan hal yang vital untuk instansi karena dengan internal control yang bagus maka produktifitas instansi juga akan baik. Internal control yang baik mampu menunjang efektivitas individu dari instansi guna memenuhi kebutuhan instansi berupa tujuan (Pratiwi, 2012).

Peningkatan kualitas pengendalian internal di setiap lembaga publik harus menjadi prioritas utama dalam pelaksanaan perubahan dan reformasi administrasi publik yang dilakukan dalam kerangka reformasi birokrasi. Kualitas pengendalian internal semakin baik, keinginan dan kemampuan untuk menyalahgunakan kekuasaan dan kewenangan diyakini semakin berkurang.

Dari lima unsur sistem pengendalian intern negara di beberapa SKPD Kab Aceh Besar, telah dilaksanakan dengan baik berdasarkan Peraturan Pemerintah Nomor 60 Tahun 2008 tahun ini tentang sistem kontrol. Pedalaman Negara. Namun demikian, masih ada beberapa hal yang masih perlu dibenahi dan ditingkatkan guna menciptakan sistem pengendalian intern yang lebih efektif terlibat sistem pembayaran tunai di instansi tersebut (BPK, 2018).

Percepatan penerapan sistem pengendalian intern juga tertuang dalam PP No 2 Tahun 2015 mengenai RPJMN 2015-2019, yang menyebutkan persentase kementerian / departemen / otoritas yang melakukan sistem pengendalian intern negara sudah $100 \%$, maka komitmen pemerintah.

Selain itu, tujuan utama pembangunan pemerintah dalam RPJMN 2015-2019 ialah meningkatkan kualitas tata kelola pemerintahan yang bersih, efisien, dan andal, dengan parameter penyelenggaraan birokrasi yang bersih dan akuntabel. Hal ini ditandai dengan peningkatan integrasi ASN, peningkatan kemampuan pengawasan dan kemandirian, peningkatan pelaporan keuangan dan kinerja pemerintah, serta peningkatan transparansi dalam pengadaan barang / jasa. Indikator kinerja untuk mengukur kemajuan pembangunan aparatur negara antara lain tingkat kematangan penerapan sistem pengendalian intern negara (SPVK) tahun 2019 pada level 3 (level tertentu). Pengukuran kematangan penerapan SPIP dapat memberikan gambaran tentang kematangan / keunggulan penerapan SPIP.

Berdasarkan dari hasil laporan BPKP tentang penilaian maturitas penyelenggaraan SPIP Aceh besar tahun 2016 didapatkan data bahwasanya Karakteristik umum dari pelaksanaan SPIP menunjukkan bahwasanya Kabupaten tersebut Aceh Besar yakni mengimplementasi aturan controlling beberapa aktivitas inti unit instansi di lingkungan Pemerintah Kabupaten Aceh Besar sesuai dengan Peraturan Pemerintah Nomor 60 Tahun 2008; Pemberian kebijakan dan prosedur bagi beberapa unit instansi kunci di lingkungan pemerintahan Kabupaten Aceh Besar; Kegagalan dalam mematuhi kebijakan dan prosedur beberapa bidang kegiatan utama unit instansi internal pemerintah kabupaten Aceh Besar dan dokumentasi yang konsisten; Efektivitas penerapan aturan pengendalian terlibat bidang kegiatan utama unit instansi internal belum sepenuhnya dinilai oleh Pemerintah Kabupaten Aceh Besar secara berkala dan terdokumentasi; dan tidak melakukan aktivitas berkelanjutan apa pun yang terintegrasi ke dalam pelaksanaan seluruh aktivitas yang didukung oleh pemulihan otomatis menggunakan aplikasi komputer.

Salah satu hal yang harus diperhatikan oleh pemerintah dalam sistem pengendalian intern ialah melakukan analisis yang tepat terhadap sistem pengendalian intern, perlu integrasi dan internalisasi pengendalian internal (BPKP, 2016).

\section{Kajian Pustaka dan Kerangka Konseptual Teori Stewardship}

Menurut Donaldson dan Davis (1991) dalam Anton (2010) Manajemen menunjukkan bahwasanya tidak terdapat kondisi dimana pihak manajer tertarik untuk mencapai target perorangan, tetapi berfokus pada target terpenting yakni kebutuhan instansi. teori yang mengilustrasikan kondisi dimana manajer tidak termotivasi oleh tujuan individu, tetapi lebih terfokus pada pencapaian tujuan akhir utama mereka untuk kebaikan instansi merupakan teori manajemen stratejik (Sanjaya, 2017).

\section{Sistem Pengendalian Intern}

Versi pengendalian internal COSO ialah sistem pengendalian internal yang mengintegrasikan seluruh aspek operasi dan keuangan perusahaan, termasuk manajemen senior dan karyawan, sasaran dan risiko bisnis, dan mencakup seluruh divisi aktivitas instansi. Penerapan pengendalian internal versi COSO diharapkan dapat mengurangi potensi penyimpangan dalam berbagai bentuk, meningkatkan kualitas laporan 
keuangan dan memastikan kepatuhan terhadap persyaratan regulasi.

\section{Sistem Pengendalian Intern Pemerintah}

Menurut Hoesada (2016: 181), SPIP mengatur struktur internal control system yang dikeluarkan pada tahun 1992 oleh Panitia yang mensponsori "kerangka COSO". SPIP merupakan sistem pengawasan yang komprehensif oleh pemerintah pusat dan pemerintah daerah.

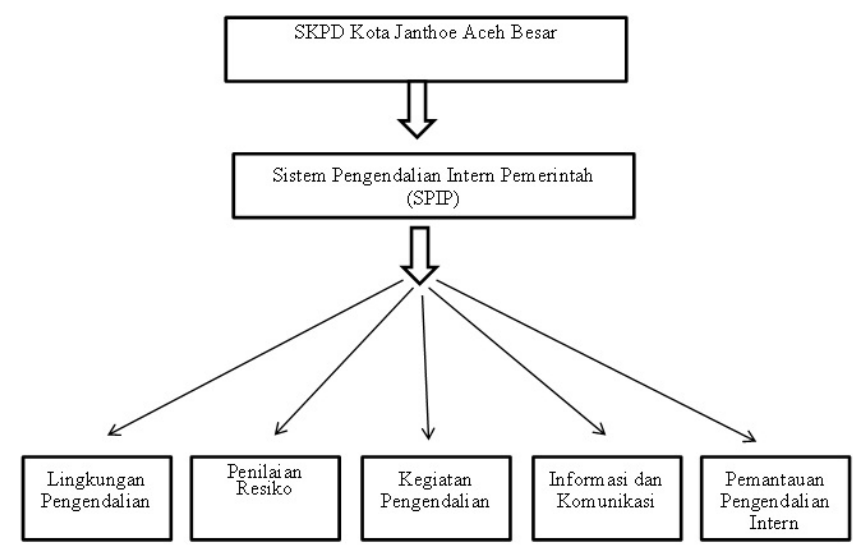

\section{Metode Penelitian}

\section{Jenis dan Pendekatan Riset}

Jenis riset yang dipakai dalam riset ini ialah metode riset kualitatif. Menurut Moleong (2005: 6), riset kualitatif ialah riset yang berusaha mengerti kejadian yang dirasakan subjek riset.

Pendekatan yang dipakai dalam riset ini ialah deskriptif yakni: riset yang didukung oleh data riset yakni pengumpulan data dan fakta tentang objek yang menarik.

\section{Lokasi Penelitian}

Riset ini dilaksanakan pada SKPD Aceh Besar khususnya di kota Janthoe Kabupaten Aceh Besar yakni Inspektorat, Bappeda, Dinas Pendidikan, DPMPTSP, Dinkes, dan BPKD.

\section{Subjek dan Objek Penelitian}

Pada riset ini "informan" dipakai untuk objek riset. Kriteria terpilih pemberi informasi memiliki wawasan mengenai SPIP, sedangkan informan utama dalam riset ini ialah Sekretaris Inspektorat, Kabid riset dan pengendalian dan kerjasama pembangunan Bappeda, Kabid pembinaan ketenagaan Dinas Pendidikan, Kabid Pengendalian DPMPTSP, Kabid
Sumber dayaDinkes, dan Kabid Keuangan BPKD Aceh Besar.

\section{Instrumen penelitian}

Dalam riset kualitatif, penyidik ialah alat utama untuk mengumpulkan dan menginterpretasikan data, dipandu oleh instruksi wawancara. Dengan mengamati dan memberikan wawancara rinci, orang bisa mengerti penerapan SPIP pada SKPD Kabupaten Aceh Besar.

\section{Teknik Pengumpulan Data}

Berdasarkan Arikunto (2010: 203) alat riset ialah alat atau sarana yang dipakai peneliti supaya dapat mengkoleksi data supaya pekerjaan menjadi lebih mudah, lebih baik, lebih akurat, lebih lengkap, dan lebih sistematis sehingga lebih mudah untuk diolah. Metode pengumpulan data yang dipakai dalam riset ini antara lain wawancara, dokumentasi.

\section{Teknik Analisis Data}

Berbagai model dalam analisis data kualitatif, analisis data dikerjakan dalam kajian penerapan SPIP di SKPD Kabupaten Aceh Besar, memakai jenis penelitian model Miles \& Huberman pada progres analisis datanya. Miles dan Huberman (Sugiyono, 2015: 337) memperlihatkan bahwasanya kegiatan analisis data kualitatif dikerjakan dengan interaktif dan kontinu hingga rampung. Langkah analisis data Miles \& Huberman yakni koleksi data, reduksi data, penyajian data, verifikasi atau penarikan kesimpulan.

\section{Pengujian Keabsahan Data}

Untuk mendapatkan kesimpulan dan interpretasi yang valid, perlu dilakukan pengecekan reliabilitasnya. Kepercayaan berkaitan dengan seberapa besar Anda bisa mempercayai kebenaran hasil riset. Pada riset ini validasi data riset dilaksanakan dengan menambah persistensi, triangulasi, menggunakan bahan refernsi.

\section{Hasil Riset dan Pembahasan Gambaran Umum Lokasi Riset}

Riset ini dilaksanakan pada SKPD Kabupaten Aceh Besar khususnya yang terletak di kota Janthoe yakni Inspektorat, Bappeda, Dinas Pendidikan, DPMPTSP, dan BPKD. 


\section{SPIP Pada SKPD Kabupaten Aceh Besar}

SKPD Kabupaten Aceh Besar ialah instansi publik yang fokus pada peningkatan efisiensi pendapatan, sebagai penyelenggara bagian dari kekuasaan negara dan tugas dekonsentrasi di bidang daerah kabupaten Aceh Besar, SKPD Kabupaten Aceh Besar memainkan peran secara stratejik, yakni: "Sebagai Direktur Utama PAD, dipakai untuk membiayai belanja daerah secara akuntabel, transparan, efisien dan efektif.

Jadi, karena unsur-unsur pengendalian internal berada di bawah paragraf. 60 Tahun 2008 tentang SPIP. Selain itu, peneliti mencoba menunjukkan bagaimana penerapan SPIP tercermin di dalamnya SKPD Kabupaten Aceh Besar.

\section{Lingkungan Pengendalian}

Secara keseluruhan unsur lingkungan pengendalian SKPD Aceh Besar sudah terpadu dan pelaksanaannya telah sesuai prosedur. Hal ini dapat dilihat antara lain: Lingkungan pengendalian yang terlibat dengan struktur instansi yang memenuhi permintaan, hingga penyekatan akses yang akan diberlakukan melihaat struktur instansi. Unsur control environment dikaitkan dengan pendelegasian kewenangan dan tanggungjawab yang tepat, sehingga penyekatan akses bisa dilaksanakan bertahap menurut kewenangan dan tanggungjawab. Unsur lingkungan pengendalian dikaitkan dengan konsistensi terhadap tingkat kompeten, oleh karena itu, ketika mendelegasikan wewenang dan tanggung jawab kepada karyawan, perhatian diberikan pada kompetensi karyawan yang ditugaskan. Unsur lingkungan pengendalian dikaitkan dengan menjaga integritas dan nilai-nilai etika supaya pejabat yang memiliki akses kekuasaan tidak bertemu. Informasi serta komunikasi mengacu pada interaksi intern agar bisa memberikan pengetahuan tentang tingkat keberhasilan penyekatan akses. Unsur pemantauan dihubungkan dengan pemantauan secara terus menerus agar dapat dipastikan bahwasanya dewan direksi sudah memberi arahan supaya penyekatan bisa efektif.

\section{Penilaian Risiko}

Berdassrkan perrnyataan diatas menunjukkan bahwasanya unsur SPIP dalam hal penilaian resiko di SKPD Kabupaten Aceh Besar menunjukan bahwasanya strategi operasional konsisten mengenai rencana penilaian risiko. Hal ini sejalan dengan Utoyo (2011), Untuk dapat meningkatkan kinerja dan tata kelola instansi, Anda memerlukan manajemen risiko perusahaan (ERP) terintegrasi, pengendalian internal, dan perlindungan penipuan. Prinsip inti pengendalian internal menurut COSO ialah manajemen risiko yang baik, dan pengendalian internal sangat penting untuk keberhasilan jangka panjang seluruh instansi. Langkah pertama dalam pengelolaan risiko yang tepat ialah melakukan penilaian risiko untuk menyusun list tampilan dan jumlah resiko serta daftar tanggapan resiko.

\section{Kegiatan Pengendalian}

Karena adanya penyesuaian dengan tugas, fungsi, karakteristik, dan kompleksitas masing-masing instansi, maka penerapan unsur kegiatan pengendalian dapat berbeda pada masing-masing SKPD. Karenanya, diperlukan analisa kepada pelaksanaan unsur aktivitas pengendalian supaya mengikuti standar yang berlaku sesuai dengan PP No 60 Tahun 2008. SKPD Kabupaten Aceh Besar melakukan aktivitas pengendalian seperti yang dirumuskan pada PP No. 60 Tahun 2008 tentang sistem pengendalian intern pemerintah, tapi memerlukan implementasi yang lebih dalam dan komitmen yang tinggi.

\section{Informasi dan Komunikasi}

Sarana informasi dan komunikasi yang dipakai oleh SKPD Kabupaten Aceh Besar telah menjejali unsur SPIP yang baik, tapi dibutuhkan pembaruan sistem informasi yang dipakai agar tercipta pengetahuan yang baik dan dapat ditelaah untuk mengambil keputusan.

\section{Pemantauan}

Berdasarkan hasil wawancara, dapat disimpulkan bahwasanya Monitoring dilakukan melalui kegiatan monitoring / pengendalian manajemen secara berkala terlibat dengan pengimplementaian kewajiban baik oleh pimpinan ataupun peninjauan berupa kerjasama antara satu pihak dengan yang lain untuk memastikan arahan, panggilan ke service manager bila memerlukan pengetahuan terlibat masalah yang ada guna memperkecil penyelewengan dan efisiensi dalam mencapai target instansi. Jumlah kegiatan peninjauan 
yang diinginkan untuk sebuah instansi bergantung pada empat elemen SPIP lainnya.

\section{Kontribusi SPIP dalam SKPD Kabupaten Aceh Besar}

Sistem pengendalian intern yang dijalankan dilingkungan pada SKPD Kab Aceh Besar sesuai dengan Peraturan Pemerintah No. 60 Tahun 2008 SPIP, dimana segala macam upaya telah dilakukan SKPD Kabupaten Aceh Besar, yakni dengan memberikan binaan dan pamantauan terhadap karyawan dan menerbitkan berbagai aturan yang memberi dampak baik terhadap sistem kendali di lingkungan instansi dan mengurangi tingkat penyelewengan terhadap tujuan dinas.

SPIP memberikan manfaat bagi SKPD Kabupaten Aceh Besar memberikan jaminan yang memadai bahwasanya efisiensi dan efektivitas dicapai dalam mencapai tujuan administrasi publik, reliabelnya sebuah laporan keuangan, perlindungan harta publik serta loyalitas kepada aturan negara yang berlaku. Yang mana telah berlaku umum, SPIP sudah menjadi suatu ketentuan perundang-undangan dalam bentuk PP yang maknanya sudah diharuskan sebagai harapan pemerintah dalam menuntaskan pelaksanaan regulasi restorasi bagian keuangan. Dengan demikian evaluasi kepada keadaan SPIP sebuah organisasi pemerintahan, berikutnya dapatdijadikan sebagai dasar penilaian, implementasi SPIP pada organisasi pemerintahan merupakan suatu progres yang dilanjutkan dengan implementasi SPIP, dimulai dari tingkat knowledge sampai dengan implementasinya.

\section{Kesimpulan dan Saran}

\section{Kesimpulan}

Kajian ini didasari pada implementasi PP No. 60 tahun 2008. SPIP pada SKPD Kabupaten Aceh Besar mempertimbangkan elemen SPIP diterapkan oleh SKPD Kabupaten Aceh Besar. Secara keseluruhan kelima unsur SPIP pada SKPD Kabupaten Aceh Besar ni telah dilaksanakan dengan baik dan berkomitmen penuh untuk pelaksanaan SPIP.

\section{Saran}

Bagi SKPD Kabupaten Aceh Besar dalam rangka meningkatkan penyelenggaraan SPIP yang lebih terikat pada unsur SPIP, sehingga kesalahan dalam pelaksanaan SPIP dapat diminimalisir.
Peneliti selanjutnya perlu mendalami lebih dalam seluruh unsur SPIP, mengingat kontribusi SPIP yang menitikberatkan pada baik buruknya hasil pelaporan bidang keuangan menggunakan kuesioner sbg metode riset agar dapat memperoleh ilustrasi yang relevan perihal tingkat pelaksanaan SPIP, seluruh unsur pada Checklist pengujian internal control di PP 60 tahun 2008 juga dimasukkan pada kuesioner yang memakai pekerja sebagai subjek riset untuk mengoptimalkan riset. Pemberi informasi pada riset.

\section{Daftar Pustaka}

Hoesada, Jan. 2016. Bunga Rampai Akuntansi Pemerintahan. Jakarta: Salemba Empat.

Ikhtisar Hasil Pemeriksaan Semester I BPK Tahun 2015. Moeller, Robert R., 2007. COSO Enterprise Risk Management: Understanding

Mamuaja. 2016. "Analisis Efektivitas Penerapan Sistem Pengendalian Intern

Terhadap Kinerja Instansi Pemerintah Di Dinas Pendapatan Kota Manado" ejournal.unsrat.ac.id. Vol 4, No 1 (2016).

Moleong, Lexy J. 2005. Metodologi Penelitian Kualitatif. Bandung: Remaja Rosdakarya

Nasution, Achmad. 2016. Analisis Penerapan Sistem Pengendalian Intern Pemerintah (SPIP). e-Journal UNISRI. ISSN 2355-4223. Vol 3. No 1, Januari-Juli 2016. Hal 76, 78-79. Universitas Slamet Riyadi

Pertiwi, Dian. 2016. "Implementasi Sistem Pengendalian Intern Pemerintah (SPIP) Dalam Mewujudkan Good Governance Pada Dispenda Provinsi Sulawesi Selatan. Skripsi. Universitas Islam Negeri Alauddin Makassar.

Sugiyono. 2010. Memahami Penelitian Kualitatif. Bandung: Alfabeta

Undang-Undang Nomor 1 Tahun 2004 Tentang Perbendaharaan Negara

Undang-Undang Nomor 32 Tahun 2004 Tentang Pemerintah Daerah 